Article

\title{
Research on a Gas Index Reflecting the Sorption Process on Carbon Materials in Coal Mines
}

\author{
Karolina Wojtacha-Rychter ${ }^{1}$ and Adam Smoliński ${ }^{2, *}$ (i) \\ 1 Department of Mining Aerology, Central Mining Institute, Pl. Gwarków 1, 40-166 Katowice, Poland; \\ kwojtacha@gig.eu \\ 2 Central Mining Institute, Pl. Gwarków 1, 40-166 Katowice, Poland \\ * Correspondence: smolin@gig.katowice.pl; Tel.: +48-32-259-2252
}

Received: 14 June 2018; Accepted: 10 July 2018; Published: 14 July 2018

\begin{abstract}
Based on the concentration of gases such as propylene and ethylene in the atmosphere of a mine, it is possible to assess the development of a mine fire. With the increase of coal temperature, an increased emission of these gases has been observed. However, the experiment results presented in this paper prove that the use of propylene and ethylene for the prediction of the spontaneous combustion of coal have some limitations. It was found that during a flow of gas mixture through the sorption column, propylene and ethylene were sorbed on coal. This phenomenon manifests in smaller amounts of gases at the outlet of the sorption column. By comparing the concentration of ethylene to propylene at the inlet of the column, it was concluded that the ratio was usually below 3 , whereas the range of the ratio at the end of the column was between $0.6-353$. The value of gases ratio changed depending on the type of coal material in the column. The results of this experiment provide useful information that the quantitative relation between ethylene and propylene concentrations may indicate the occurrence of the sorption process on carbon materials in coal seams.
\end{abstract}

Keywords: propylene; ethylene; sorption; mine fire; coal; index

\section{Introduction}

Coal remains the dominant fuel in the global energy structure, despite the fact that a decrease in the share of coal in global energy consumption has been observed, caused by an increase of share of renewable fuels and gas. The constant demand for coal makes it necessary to extract coal from new and deeper deposits. The increase in the depth of extraction can be a reason for many natural hazards which may result in serious accidents in mines. Out of these, self-heating of coal is the phenomenon which leads to fires in coal mines across the world. It occurs when the volume of air flow through the coal seam is sufficient to support oxidation reaction but not enough to carry off the heat produced by the coal oxidation [1]. Negative results of this natural process are reflected in the necessary isolation of the threatened area, massive destruction of the valuable resource of coal, and a risk for the work safety of miners. Various methods have been developed and introduced to mining practice in order to accurately detect fires and their positions in underground mines [2,3]. In coal-producing countries in the world, the most used method is based on the analysis of the mine air composition, which consists of determining the gaseous components, both under safe conditions and when there is any change in composition of mine air [4]. Data obtained over a period of time in safe conditions constitutes a background level for daily measurements at the control stations. Additionally, the routine results of quantitative analyses of gaseous components are compared with the reference gas emission profile depending on the temperature obtained during the laboratory tests of coal heating in the reactor. The composition of multi-component gas mixture is measured through chromatographic analyses. Carbon monoxide, as a commonly occurring oxidation product, is the most frequently recommended 
gas in the detection of fire hazards in all countries [5-8]. Carbon monoxide is produced at lower temperatures and its concentration increases with the change of coal temperature; therefore, the use of this gas in fire detection seems to be reliable. However, fire hazard assessment based on carbon monoxide has some limitations, due to the fact that the high concentration of carbon monoxide may not be related to the oxidation process $[9,10]$. Therefore, the analysis of the composition of the mine air is complemented with monitoring of changes in other gases, such as ethylene and propylene. They are useful indicators because the concentration of those gases in mine atmosphere also significantly increases with coal temperature. However, the temperature at which unsaturated hydrocarbons becomes noticeable is higher than for carbon monoxide. A significant problem in forecasting fire based on the gas content in the mine is that propylene and ethylene may also subject to sorption on coal. Numerous studies have demonstrated that the above gases flowing through the coal seam may become trapped by physical or chemical sorption in the coal porous structure [11-13]. The sorption process refers to the phenomenon occurring at the solid-gas interface. In physical sorption, a multi-molecular layer is formed by the weak interaction between adsorbate-adsorbent (via van der Waals forces) [14]. In chemical sorption, the monolayer is formed by the strong chemical bonds. The sorption process is described by gas adsorption isotherms. There are several well-known models used to quantitatively describe the sorption isotherms: Langmuir, Brunauer-Emmett-Teller (BET), Dubinin-Radushkevich (DR) and Dubinin-Astakhov (DA), respectively [15-18]. To effectively describe the gas adsorption behavior at low pressure the Langmuir model is recommended [19]. Unsaturated hydrocarbons have a double bond between carbon atoms that promotes their reactivity, so they can react readily with active functional groups on the surface of coal. A sorption of combustion gases can be reflected in the change of gas concentration in the gas emission profile. However, this phenomenon may cause differences between the results obtained under real and laboratory conditions, where the sorption process does not occur. The objective of this paper is to propose a sorption index, which would allow the determination of whether the change of the ethylene or propylene concentration in mine air corresponds to the sorption process on carbon materials. This approach would provide guidance for more effective prevention of the spontaneous combustion of coal.

\section{Materials and Methods}

The laboratory-scale installation for studying the sorption process of gas mixture (including ethylene and propylene) on coal materials is presented in Figure 1.

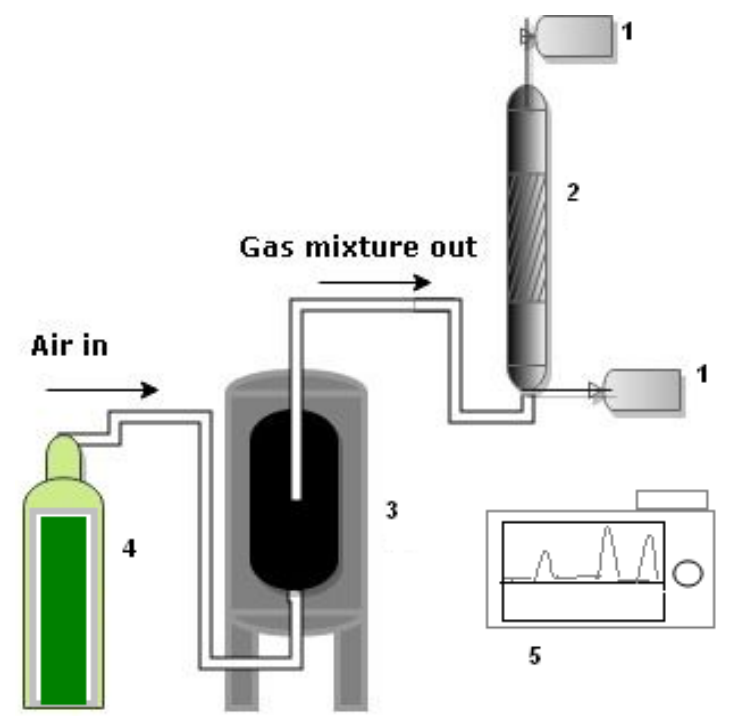

Figure 1. Experimental installation: (1) Tedlar bag; (2) sorption column; (3) reactor; (4) oxidation medium tank; (5) gas chromatograph. 
A cylindrical fixed bed reactor with an external diameter of $0.07 \mathrm{~m}$ and height of $0.18 \mathrm{~m}$ constituted the part of the installation where a simulated self-heating of coal was performed. The reactor was heated using a resistance furnace mounted on a specially designed tripod. The oxidizing agent in the studied process was synthetic air supplied from a gas cylinder. The amount of gas generated during the heated process was measured by means of a mass flow meter for aggressive gases. A gas mixture produced in the reactor was directly released via the sorption column with a width of $0.025 \mathrm{~m}$ and height of $1 \mathrm{~m}$. Tedlar bags with airtight valves were used to collect gas samples. The composition of the gaseous mixtures exiting the reactor and sorption column was analyzed using a gas chromatograph. A Hewlett Packard 6890 Series gas chromatograph with flame ionization detector was used for the detection of ethylene and propylene in the multi-component gas mixture. Pure helium was applied as a carrier gas. The compounds were burnt in a mixture of hydrogen and synthetic air flame.

The measurements of sorption process were performed on coals collected from Polish mines located in the Upper Silesia Coal Basin. The characteristic of these samples, in the form of carbon and oxygen elements content, is given in Table 1.

Table 1. Characteristics of coals used as sorbents and heated in the reactor.

\begin{tabular}{ccc}
\hline Sample & Carbon, $\% w / w$ & Oxygen, $\% w / w$ \\
\hline 1 & 61.39 & 4.84 \\
2 & 67.70 & 11.42 \\
3 & 89.06 & 1.12 \\
4 & 76.93 & 6.37 \\
5 & 81.01 & 6.83 \\
6 & 74.66 & 9.02 \\
7 & 64.18 & 12.78 \\
8 & 79.55 & 7.39 \\
9 & 85.58 & 3.38 \\
10 & 63.69 & 10.32 \\
\hline
\end{tabular}

The elemental analysis of samples was performed in the accredited Laboratory of Solid Fuels Quality Assessment of the Central Mining Institute in accordance with the relevant standard in force: PN-G-04571:1998 and the internal procedure. In the study, coal samples of particle size from 1.0-2.0 mm and weight $0.4 \mathrm{~kg}$ were placed in the reactor and heated to the desired temperatures. The measurements were performed at various temperatures of coal heating in the reactor: $373 \mathrm{~K}, 423 \mathrm{~K}, 473 \mathrm{~K}$ and $523 \mathrm{~K}$. After the desired temperature was obtained, an oxidizing medium was injected. The synthetic air was the medium in the process. As the result of oxidation and decomposition of the coal, a mixture of various gaseous compounds was released, among them ethylene and propylene. This gas mixture was streamed with a flow rate of $13 \mathrm{~cm}^{3} / \mathrm{min}$ through the sorption column packed with coal with a grain class of $0.5-0.7 \mathrm{~mm}$. At the outlet and the inlet of the sorption column the gas samples were collected in Tedlar bags and their composition was determined using a gas chromatograph. In the experimental tests, both sorption column and heated reactor were filled with the same coal sample.

Based on the results from the sorption experiments, a relationship between the ethylene and propylene concentration in the multi-component gas mixtures was established both at the inlet and the outlet of the sorption column. This quantitative relation was labeled with the term of the 'sorption index' $\left(\mathrm{S}_{\mathrm{G}}\right)$ and calculated by the following equation

$$
\mathrm{S}_{\mathrm{G}}=\mathrm{C}_{\mathrm{e}} / \mathrm{C}_{\mathrm{p}}
$$

where $S_{G}$ is the sorption index, and $C_{e}$ and $C_{p}$ are the concentration of ethylene and propylene, respectively (ppm). 


\section{Results and Discussion}

The sorption index was first calculated on the basis of the concentration of ethylene and propylene in the mixture released from the coal self-heating under laboratory conditions. Then the index was calculated based on the concentration of the above gases mixture after it passed through the sorption column. In both case the index was calculated by means of Equation (1). The results obtained from calculations performed for the ten coal samples are shown in Figures 2 and 3. Figure 2 shows the sorption index value for gases flowing out of the reactor at the temperatures of $323 \mathrm{~K}, 373 \mathrm{~K}, 423 \mathrm{~K}$, $473 \mathrm{~K}$ and $523 \mathrm{~K}$, respectively. While Figure $3 \mathrm{a}-\mathrm{c}$,e represents the values at the outlet of the sorption column at the temperatures of $323 \mathrm{~K}, 373 \mathrm{~K}, 423 \mathrm{~K}, 473 \mathrm{~K}$ and $523 \mathrm{~K}$, respectively. In the case of samples with number 1-9, the sorption indices were calculated based on the results obtained and published in earlier papers [20-22], but in this study these results were used in the context of the sorption index $\left(\mathrm{S}_{\mathrm{G}}\right)$.
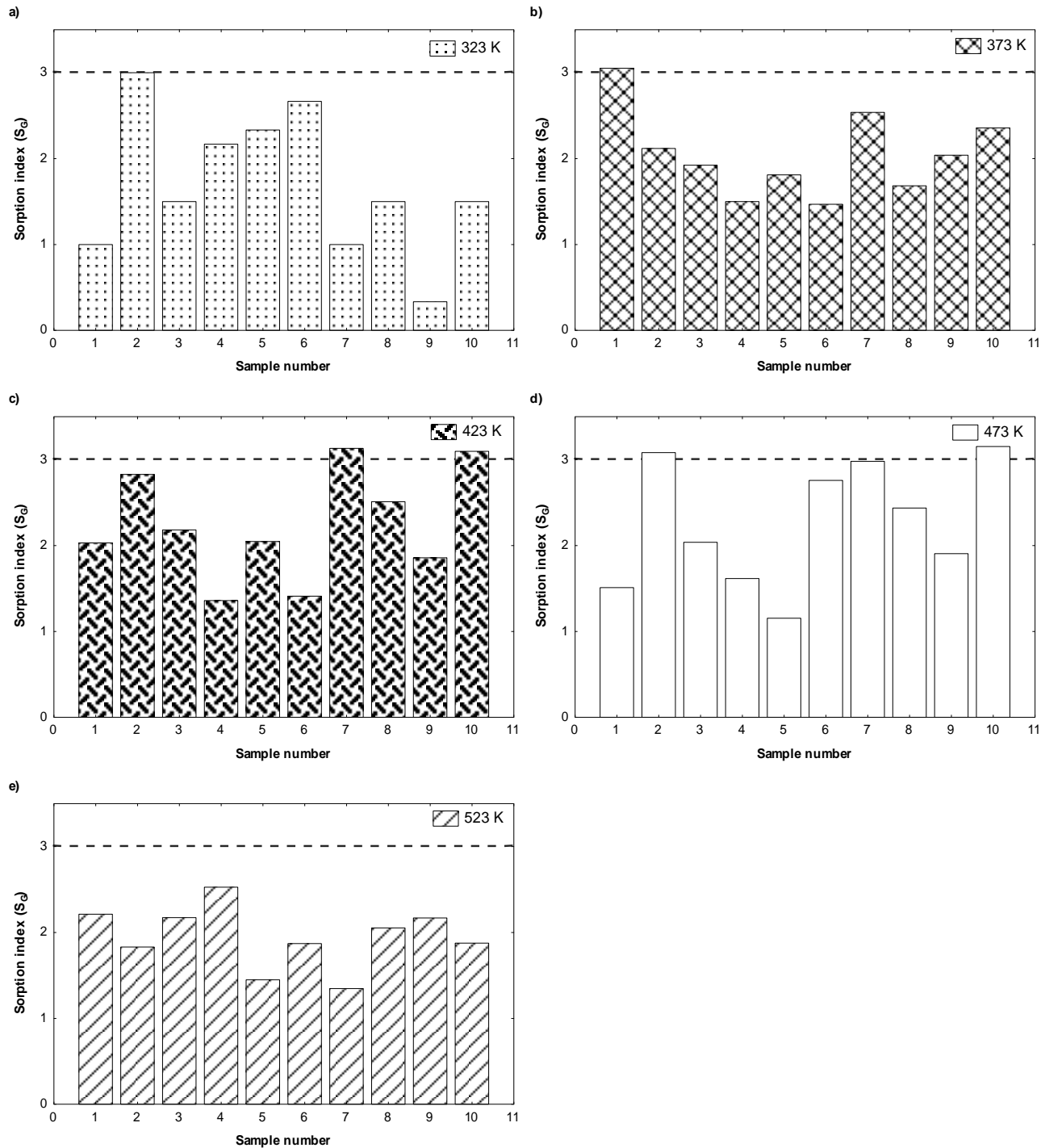

Figure 2. Sorption indices of gas mixtures generated during simulated self-heating of coal samples tested at the temperatures (a) $323 \mathrm{~K}$, (b) $373 \mathrm{~K}$, (c) $423 \mathrm{~K}$, (d) $473 \mathrm{~K}$ and (e) $523 \mathrm{~K}$, respectively.

Based on the results drawn for individual samples at the inlet of the sorption column, it was established that the sorption indices of combustion products attained mostly have a value below 3 . When comparing the results for all samples, it is difficult to detect any distinct relationship between the values of sorption indices and coal temperature or rank. Although, it can be noticed that the 
low-rank coals (samples 1, 2, 7, 10) showed slightly higher values of index at the higher temperatures than the high-rank coals. This may be closely connected with the fact that a small volume of propylene produced in the reactor can become trapped on coal by process of sorption.
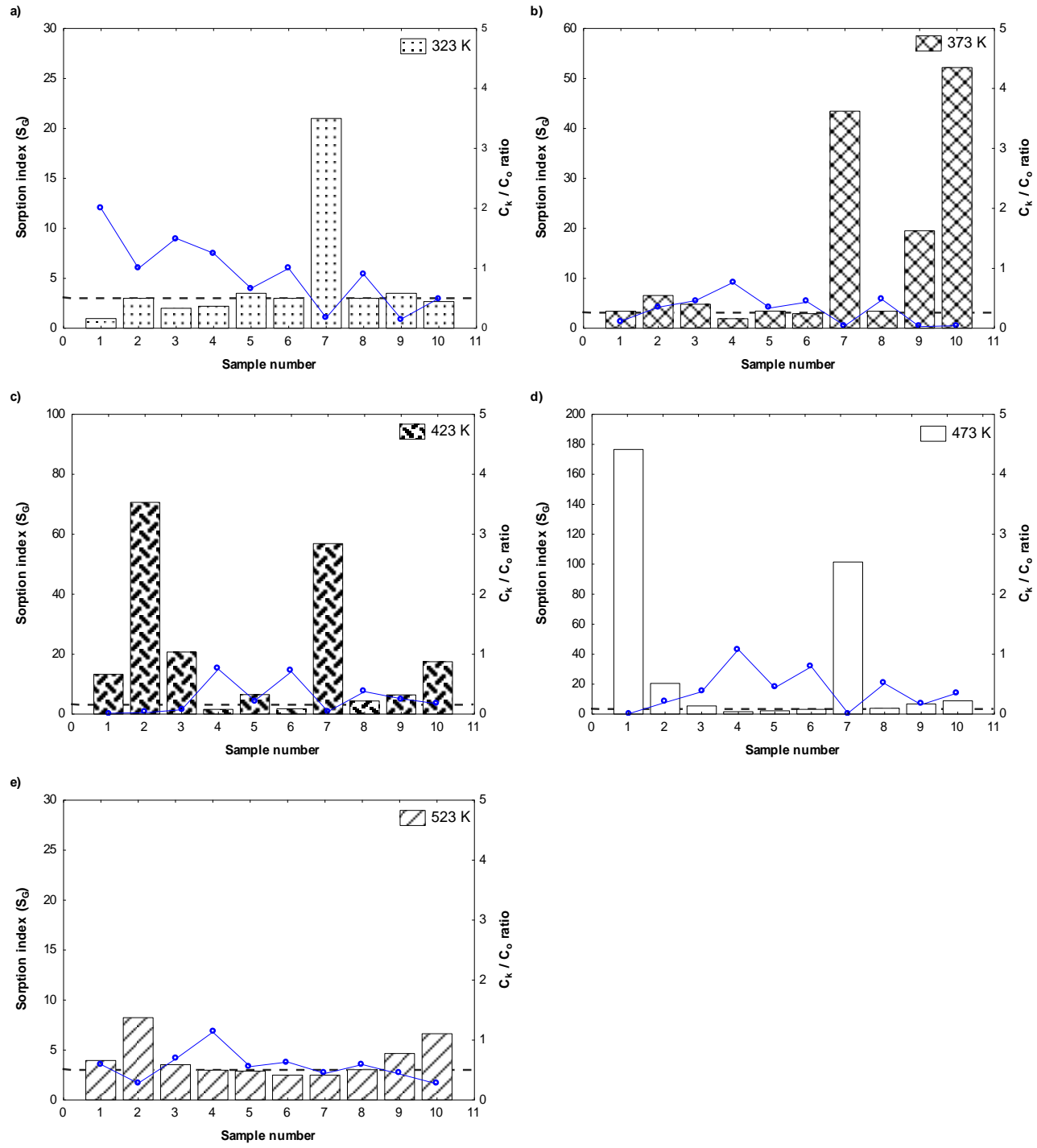

Figure 3. Sorption index of gas mixtures at the outlet of the sorption column and ratio of propylene concentration exiting the sorption column $\left(\mathrm{C}_{\mathrm{k}}\right)$ to initial gas concentration $\left(\mathrm{C}_{\mathrm{o}}\right)$ of coal samples tested at the temperatures (a) $323 \mathrm{~K}$, (b) $373 \mathrm{~K}$, (c) $423 \mathrm{~K}$, (d) $473 \mathrm{~K}$ and (e) $523 \mathrm{~K}$, respectively.

The values of the sorption index calculated for the propylene and ethylene concentration in a gas mixture exiting the sorption column demonstrate (see Figure 3) that there are some samples showing a level of the sorption indices above 3. This trend is observed both at the higher temperatures-373 K, $423 \mathrm{~K}, 473 \mathrm{~K}$-and with coals with the lower carbon content, below $70 \% w / w$. Moreover, the relationship between the values of sorption index and ratio of propylene concentration at the outlet $\left(C_{k}\right)$ to the inlet $\left(C_{o}\right)$ of the sorption column is presented in Figure 3. It can be observed that the highest sorption index corresponds with the lowest value of ratio. Thus, it can be inferred that high values of sorption index are affected by the sorption process of propylene on low-rank coal. The correlation between the carbon content, oxygen amount and of the average value of the index for individual samples is shown in Figure 4. 


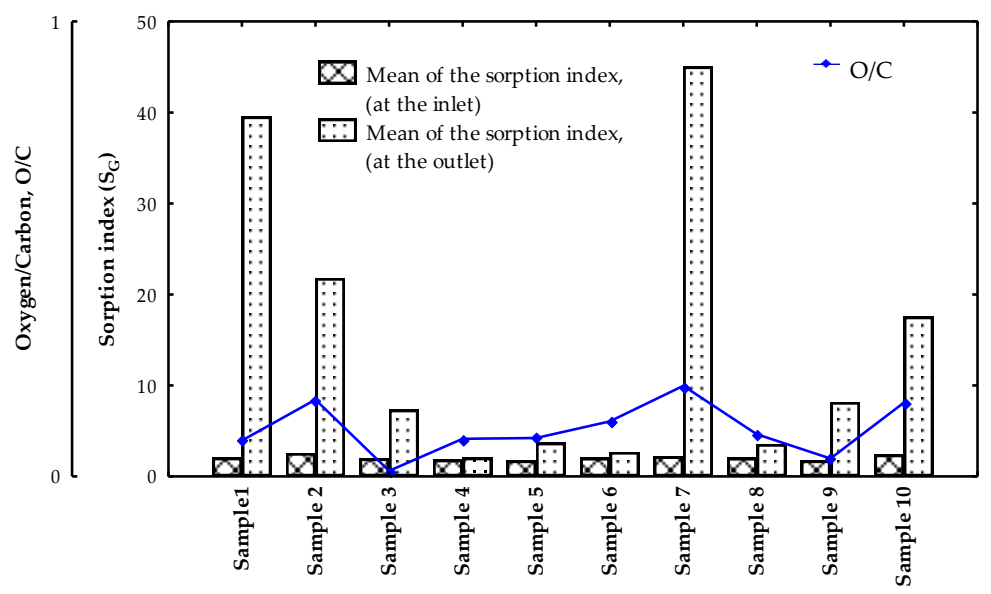

Figure 4. Means of the sorption index and content of carbon element for all tested samples.

It can be noticed that, for example, Sample 7, with a carbon content of $64.18 \% w / w$, has a mean of $\mathrm{C}_{2} \mathrm{H}_{4} / \mathrm{C}_{3} \mathrm{H}_{6}$ ratios 45.06 and standard deviation of 37.80 ( $\max =102$ and $\min =2.49$ ), whereas Sample 8, with a carbon content of $79.55 \% w / w$, has a mean value of 3.55 and standard deviation of 0.6 $(\max =4.39$ and $\min =3.00)$. Additionally, compared with the elemental analysis results (expressed as the $\mathrm{O} / \mathrm{C}$ ratio for each sample), mean values of the sorption index at the outlet of the column show an upward trend with an increase of the oxygen content while the carbon content declines, which corresponds with the higher value of the $\mathrm{O} / \mathrm{C}$ ratio (between $0.16-0.20$ ). This can be explained by the fact that coals of lower metamorphism characterized by a higher oxygen content and lower carbon content have a good sorption capacity and availability of numerous polar active sites on coal surface, thus they can sorb a larger amount of propylene $[23,24]$. These oxygen-active groups such as hydroxyl, carboxyl, carbonyl and methoxyl groups present on the coal play a significant role in the sorption process of gas molecules on coals. They add polarity to the organic surface of coal because of the strong electronegative nature of oxygen atoms. In general, as the metamorphic degree declines, the content of oxygen-containing polar group tends to increase $[25,26]$.

In the next part of this study, the sorption ratios were calculated on the basis of samples taken from mine air in real conditions and referred to the results obtained in the laboratory test. A representative sample was made of 1008 objects, which were the results of chromatographic analyses of mine air samples collected over a period of time, both in safe conditions and in fire-hazard situations. The calculation of the sorption index, together with the results of the carbon monoxide concentrations for all gaseous samples, are presented in Figures 5 and 6 . Figure 5 presents the index parameters of 824 gaseous samples taken from different places underground such as longwall workings or from behind isolating dams, located in different coal mines. Based on these results, it was observed that $93 \%$ of analyzed objects indicated a sorption index below 3 , whereas only $7 \%$ of all objects had values above 3 , including $3 \%$ at the range $3-4$. Moreover, high concentration of carbon monoxide is not always correlated with a higher index value. For instance, sample numbers 396, 397, 405 and 412 were characterized by high concentrations of $\mathrm{CO}$ and had sorption indices in the range 1.1-2.2. All these samples were taken from the same mine, so it is likely that coal from that location does not have good sorption properties, thus low index values were observed. Both high concentrations of carbon monoxide and a high value of the sorption index were noticed in the case of samples 699, 694, 690 and 670. 


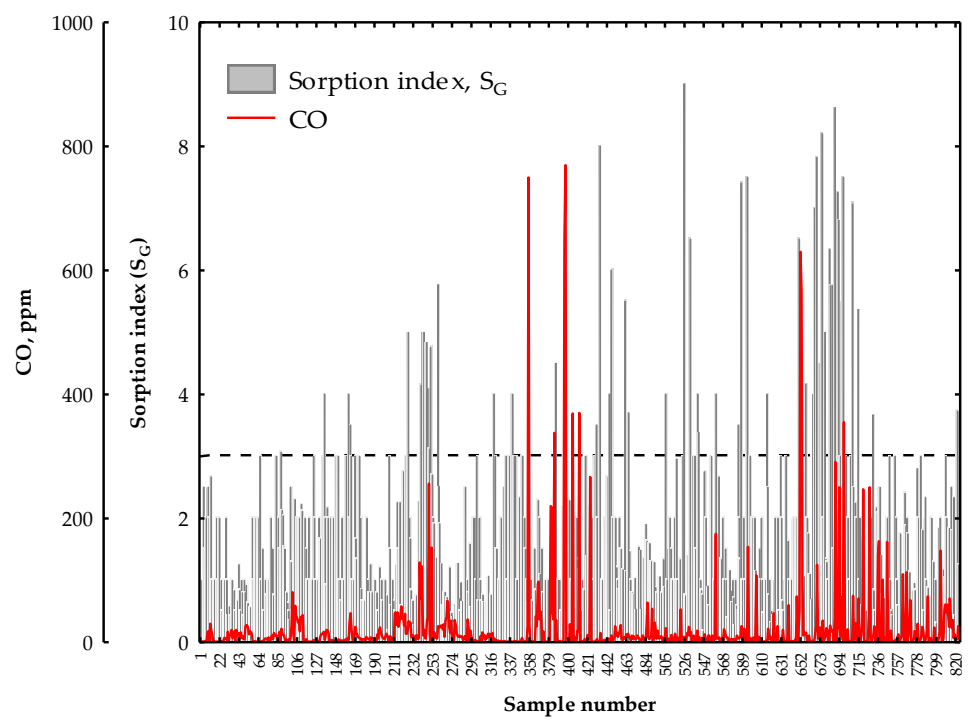

Figure 5. Sorption index and carbon monoxide concentration of samples collected under real conditions.

Figure 6 show the results of 184 samples describing the fire hazard situation in a coal mine. In the case of advanced heating, the production of combustion gases increases with an increase in coal temperature. The state of fully developed fire in the coal mine is indicated by the highest release of both the carbon monoxide and hydrocarbons such as ethylene and propylene. For samples with the numbers 1-111, the sorption index had values below 3 . As the concentration of carbon monoxide showed an upward trend, the index went up significantly.

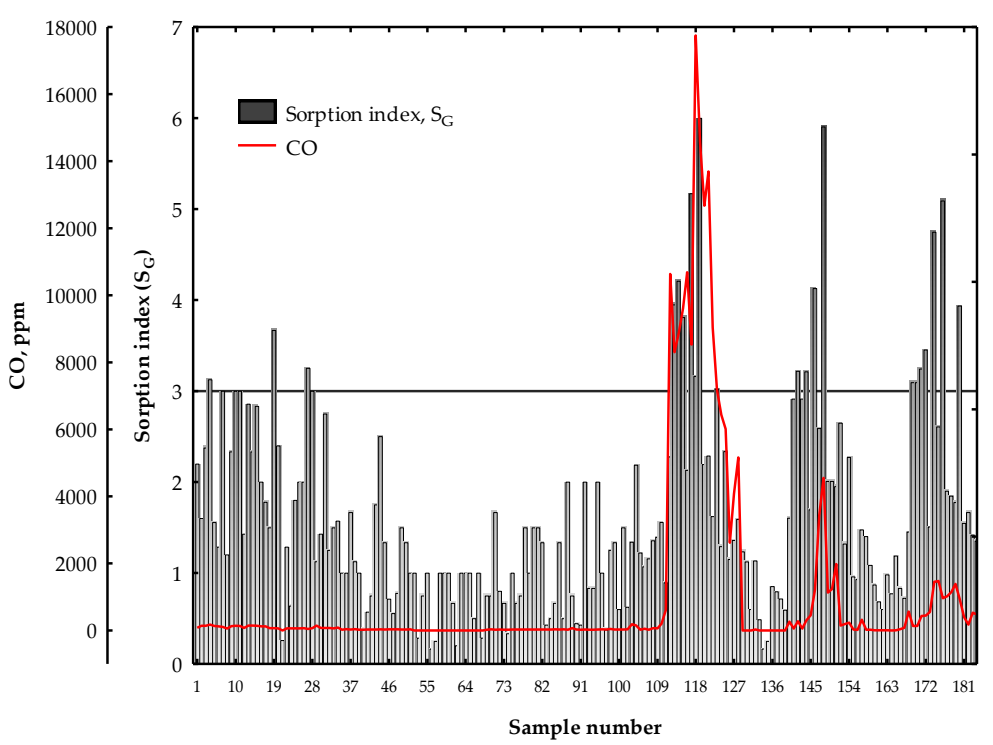

Figure 6. Sorption index and carbon monoxide concentration of samples collected under real conditions during the self-heating process.

The above results may be caused by the sorption ability of propylene on the coal surface, which is reflected in low concentrations of propylene in mine air. With the decrease of carbon monoxide in mine atmosphere, the values of sorption indices indicated a slow downward trend. 


\section{Conclusions}

The aim of the present study was to provide useful insights concerning the occurrence of fire gas sorption in underground coal mines. A laboratory-scale research stand was constructed to perform the sorption test on coal materials. The adsorbate was a gas mixture released during the self-heating of coal in the reactor. It was found that the sorption index, calculated based on the concentration of gases released during a simulated self-heating of coal, attained values below 3 . The flow of the gas mixture through the coal caused the values of indices for samples collected at the inlet of the sorption to be higher than for samples taken at the outlet of the sorption column, especially for coal of lower metamorphism. Compared with the initial concentration, the concentration of propylene at the outlet of the sorption column showed a significant downward trend, especially for coal of lower metamorphism. This result indicates that the propylene underwent sorption on coal material. Based on the results for samples taken from the mine air under real conditions, it was established that the sorption index of combustion products under safe condition underground mainly had values below 3, while under fire state the sorption index obtained values above 3 . This may be affected by the sorption process of propylene on coal material.

Based on all calculations for samples taken from both laboratory and real conditions it can be concluded that the ratio of ethylene to propylene attains values below 3 when the sorption process of propylene does not occur and the state inside the coal mine is safe. These observations allow us to conclude that the increase of value index may indicate the sorption of combustion gases. Additionally, this phenomenon was observed at higher temperatures. Future research on the sorption index $\left(\mathrm{S}_{\mathrm{G}}\right)$ should pay attention to its limitations and the factors that can affect its applicability.

Author Contributions: K.W.-R. and A.S. conceived and designed the experiments; K.W.-R. performed the experiments; A.S. and K.W.-R. analyzed the data and wrote the paper.

Funding: This work was supported by the Ministry of Science and Higher Education, Poland grant number [11333018].

Conflicts of Interest: The authors declare no conflicts of interest. The founding sponsors had no role: in the design of the study; in the collection, analyses, or interpretation of data; in the writing of the manuscript, and in the decision to publish the results.

\section{References}

1. Timko, R.J.; Derick, R.L. Detection and Control of Spontaneous Heating in Coal Mine Pillars-A Case Study; Report of Investigations RI 9553; US Bureau of Mines: Pittsburgh, DC, USA, 1995.

2. Qi, X.; Wang, D.; Hin, H.; Zhong, X. Environmental hazards of coal fire and their prevention in China. Environ. Eng. Manag. J. 2013, 12, 1915-1919.

3. Kong, B.; Li, Z.; Yang, Y.; Liu, Z.; Yan, D. A review on the mechanism, risk evaluation, and prevention of coal spontaneous combustion in China. Environ. Sci. Pollut. Res. 2017, 24, 23453-23470. [CrossRef] [PubMed]

4. Cioca, L.I.; Moraru, R.I.; Balan, L. Early detection of mine fires in a typical undermined bench face at mining division within Hunedoara energetic complex. In Proceedings of the 16th International Multidisciplinary Scientific GeoConference SGEM 2016, Albena, Bulgaria, 28 June-6 July 2016; pp. 349-356. [CrossRef]

5. Feng, X.; Adamus, A. Overview of Research and use of Indicator Gases of Coal Spontaneous Combustion in China. GeoSci. Eng. 2014, 60, 55-65. [CrossRef]

6. Brady, D. The role of gas monitoring in the prevention and treatment of mine fires. In Proceedings of the 2008 Coal Operators' Conference, Wollongong, Australia, 14-15 February 2008; Aziz, N., Ed.; University of Wollongong \& the Australasian Institute of Mining and Metallurgy: Wollongong, Australia; pp. 202-208.

7. Smith, A.C.; Miron, Y.; Lazzara, C.P. Large-Scale Studies of Spontaneous Combustion of Coal; U.S. Department of the Interior, Bureau of Mines: Washington, DC, USA, 1991.

8. Singh, A.K.; Singh, R.V.K.; Singh, M.P.; Chandra, H.; Shukla, N.K. Mine fire gas indices and their application to Indian underground coal mine fires. Int. J. Coal Geol. 2007, 69, 192-204. [CrossRef]

9. Xie, J.; Xue, S.; Cheng, W.; Wang, G. Early detection of spontaneous combustion of coal in underground coal mines with development of an ethylene enriching system. Int. J. Coal Geol. 2011, 85, 123-127. [CrossRef] 
10. Tang, Y. Sources of underground CO: Crushing and ambient temperature oxidation of coal. J. Loss Prev. Process Ind. 2015, 38, 50-57. [CrossRef]

11. Dudzińska, A. Sorption properties of hard coals with regard to gases present in the mine atmosphere. J. Earth Sci. 2017, 28, 124-130. [CrossRef]

12. Dudzińska, A.; Howaniec, N.; Smoliński, A. Experimental study on sorption and desorption of propylene on Polish hard coals. Energy Fuels 2015, 29, 4850-4854. [CrossRef]

13. Zarębska, K.; Baran, P.; Cygankiewicz, J.; Dudzińska, A. Prognosticating fire hazards in goafs in Polish collieries. AGH Drill. Oil Gas 2012, 29, 463-478. [CrossRef]

14. Zhang, Q. Development and Current Situation of Study on Theory of Methane Adsorption on Coal. Procedia Earth Planet. Sci. 2011, 3, 318-324. [CrossRef]

15. Langmuir, I. The adsorption of gases on plane surfaces of glass, mica and platinum. J. Am. Chem. Soc. 1918, 40, 1361-1403. [CrossRef]

16. Brunauer, S.; Emmett, P.H.; Teller, E. Adsorption of gases in multimolecular layers. J. Am. Chem. Soc. 1938, 60, 309-319. [CrossRef]

17. Dubinin, M.M. Modern state of the theory of gas and vapour adsorption by microporous adsorbents. Pure Appl. Chem. 1965, 10, 309-322. [CrossRef]

18. Dubinin, M. The potential theory of adsorption of gases and vapors for adsorbents with energetically nonuniform surfaces. Chem. Rev. 1960, 60, 235-241. [CrossRef]

19. Wang, Z.; Tang, X. New Insights from Supercritical Methane Adsorption in Coal: Gas Resource Estimation, Thermodynamics, and Engineering Application. Energy Fuels 2018, 32, 5001-5009. [CrossRef]

20. Wojtacha-Rychter, K.; Smoliński, A. The interaction between coal and multi-component gas mixtures in the process of coal heating at various temperatures: An experimental study. Fuel 2018, 213, 150-157. [CrossRef]

21. Wojtacha-Rychter, K.; Smoliński, A. Sorption characteristic of coal as regards of gas mixtures emitted in the process of the self-heating of coal. In Proceedings of the International Conference Energy, Environment and Material Systems (EEMS), Polanica Zdrój, Poland, 13-15 September 2017; Wzorek, M., Królczyk, G., Król, A., Eds.; EDP Sciences: Les Ulis, France, 2017; Volume 19. [PubMed]

22. Wojtacha-Rychter, K.; Smoliński, A. Multi-component gas mixture transport through porous structure of coal. Fuel 2018, 233, 37-44. [CrossRef]

23. Nie, B.; Liu, X.; Yang, L.; Meng, J.; Li, X. Pore structure characterization of different rank coals using gas adsorption and scanning electron microscopy. Fuel 2015, 158, 908-917. [CrossRef]

24. Faiz, M.M.; Aziz, N.I.; Hutton, A.C.; Jones, B.G. Porosity and gas sorption capacity of some eastern Australian coals in relation to coal rank and composition. In Proceedings of the Coalbed Methane Symposium, Townsville, Australia, 19-21 November 1992; Beamish, B.B., Gamson, P.D., Eds.; James Cook University of North Queensland: Townsville, Australia; Volume 4, pp. 9-20.

25. Gensterblum, Y.; Busch, A.; Krooss, B.M. Molecular concept and experimental evidence of competitive adsorption of $\mathrm{H}_{2} \mathrm{O}, \mathrm{CO}_{2}$ and $\mathrm{CH}_{4}$ on organic material. Fuel 2014, 115, 581-588. [CrossRef]

26. Zhou, G.; Xu, C.; Cheng, W.; Zhang, Q.; Nie, W. Effects of Oxygen Element and Oxygen-Containing Functional Groups on Surface Wettability of Coal Dust with Various Metamorphic Degrees Based on XPS Experiment. J. Anal. Methods Chem. 2015, 1, 1-8. [CrossRef] [PubMed]

(C) 2018 by the authors. Licensee MDPI, Basel, Switzerland. This article is an open access article distributed under the terms and conditions of the Creative Commons Attribution (CC BY) license (http:/ / creativecommons.org/licenses/by/4.0/). 